\title{
OS “TENDEIROS DA SERRA DO BOTUCARAII": ESTRATÉGIAS MERCANTIS E CULTURAIS NO MEIO RURAL DO CENTRO-NORTE DO RS
}

\author{
THE "TENDEIROS DA SERRA DO BOTUCARAI": \\ MARKET AND CULTURAL STRATEGIES IN THE COUNTRY \\ SIDE OF THE NORTH CENTER OF RS
}

Jỗo CARLos TEDESCO ${ }^{1}$

Recebido em: 01/05/2013

Aprovado em: 02/07/2014

\section{RESUMO}

Neste artigo, analisamos aspectos da produção e comercialização de tendeiros na BR 386, nos municípios de Fontoura Xavier e São José do Erval, no centro-norte do Rio Grande do Sul. Nesse sentido, buscamos evidenciar algumas estratégias de produção e marketing em torno do "produto colonial" e artesanal como fatores de otimização nas vendas diretas ao consumidor na beira dessa rodovia. A fundamentação teórica utilizada para a análise gira em torno de noções como "economia da tradição", "produtos étnicos", "sociabilidades técnicas" e "cultura social". Tais noções auxiliam para a compreensão dos processos que viabilizam a reprodução camponesa por meio do horizonte mercantil e da identidade étnico-territorial. Concluímos que o grupo social estudado, em geral formado por pequenos agricultores de origem cabocla, consegue dinamizar o processo produtivo e mercantil, porque reproduz saberes histórico-culturais relacionados à sua memória.

Palavras-chave: Pequenos Agricultores; Tradição; Comércio; Vida Rural.

\begin{abstract}
The article analyzes aspects of the production and marketing of the "Tendeiros" on BR 386 at the cities of Fontoura Xavier and São José do Erval in the North Center of Rio Grande do Sul, wanting to show some strategies of production and marketing around the "colonial product" and handmade as facts of optimization on direct sales to highway consumers. The theory base of analysis goes around notions like "economy tradition", ethnic products, social situations techniques and social culture, that would help us to comprehend the processes that would make possible the peasant reproduction through the market horizon and the ethnic-territorial identity. We got the conclusion that the social group that we have studied, in general made by small farmers, manages to increase a productive process and the marketing showing cultural historic awareness linked to the memory.

Keywords: Small Farmers; Tradition; Commerce, Countryside Living.
\end{abstract}

${ }^{1}$ Doutor em Ciências Sociais pela Universidade Estadual de Campinas (UNICAMP), Brasil. Professor da Universidade de Passo Fundo (UPF). E-mail: joaocarlostedesco@gmail.com. 


\section{Introdução}

Buscamos analisar, neste artigo, as estratégias de organização de processos produtivos e mercantis de pequenos camponeses, em geral, de origem cabocla, estabelecidos às margens da $\mathrm{BR}$ 386 , no espaço que abarca os municípios de Fontoura Xavier e São José do Erval, centro-norte do Rio Grande do Sul. Nesse cenário, a produção agrícola, o comércio direto junto ao consumidor e o extrativismo formam o tripé que articula a organização da vida econômica dos tendeiros da "Serra do Botucaraí" ou dos "Tendeiros do Pinhão", como eles se denominam.

O texto é fruto de um estudo mais amplo que efetuamos sobre economias da tradição e estratégias de reprodução étnica de grupos sociais a partir de rotas turísticas gastronômicas no Centro-norte do estado. ${ }^{2} \mathrm{O}$ pano de fundo da análise gira em torno da relação entre tradição ${ }^{3}$ e a sua dinâmica mercantil, porque fazem parte da longa história dos grupos sociais (principalmente caboclos, trabalhadores das estâncias pastoris da região) e que, nas últimas décadas, também incorporaram a identidade de pequenos agricultores familiares.

As técnicas de pesquisa utilizadas foram entrevistas abertas e contatos diretos com tendeiros nos locais da rota na BR-386, ${ }^{4}$ com representantes da ${ }^{2}$ Nesse projeto maior de estudos, analisamos, além da rota referida ("Tendeiros do Pinhão" na Serra do Botucarai), a Rota das Salamarias, Vinhedos, ambos em Bento Gonçalves.

${ }^{3}$ Entendemos a tradição, aqui, como um horizonte de incorporação histórica do grupo e que é expressa em saberes, identidades de trabalho, formas de vida e de sociabilidade na terra, identificados historicamente na região. Ou seja, horizontes considerados como patrimônios imateriais que se revelam nos saberes, na "tradição cabocla", na vida de peão de estância nas fazendas pastoris da região, além dos hábitos de lidas com o cavalo, de uso do couro, da extração e da confecção da erva-mate, de saberes na e com a mata etc. O horizonte antropológico contribui para a compreensão de elementos ligados à tradição, à identidade étnica, aos saberes adquiridos pela experiência histórica da vida nas fazendas de gado, na vida rural, nas sociabilidades e nas organizações do grupo.

${ }^{4}$ Fizemos pesquisas de campo durante vários dias entre os meses de março a junho de 2013, intercalando visitas para participar em reuniões da Associação dos Tendeiros e de duas edições da Festa do Pinhão (2011 e 2013), em Fontoura Xavier. Nosso cenário mais específico, foram os tendeiros de Fontoura Xavier. Os tendeiros de São José do Erval foram visitados, porém, mais para efeito de conhecimento mais amplo. Desse modo, o foco da pesquisa recaiu "ao pessoal de Fontoura", como se refere a Presidente da Associação dos Tendeiros. Isso muito em função da proximidade geográfica de onde residimos, a cidade de Passo Fundo e o local da pesquisa, da participação dos integrantes da Associação, em maior grupo e, também, porque surgem nesses integrantes a identidade de todo o grupo. [Informação repetida] esfera pública municipal (Secretaria da Fazenda e da Agricultura, setor de Marketing e Comunicação, organizadores da Festa do Pinhão), com representantes da Emater e de outras entidades envolvidas (Sindicatos de Trabalhadores Rurais, Associação dos Tendeiros do Pinhão). Os questionários entregues aos entrevistados continham perguntas (ou eixos temáticos) sobre os seus vínculos histórico-culturais com alguns produtos, com os processos organizativos e de reprodução de saberes, dinâmicas e estratégias mercantis, com os festejos comunitários, com os recursos da natureza como fonte de atração, e com as "vendas casadas" de produtos, dentre outros. Foram feitas entrevistas em duas oportunidades com a presidente da Associação dos Tendeiros; quase todas as tendas, por sua vez, foram visitadas por três vezes. Essas visitas tinham por objetivo a busca de dados econômicos das relações mercantis entre a unidade familiar, a roça e a tenda, além das relações de gênero no processo produtivo e mercantil, e também, de elementos históricos que os identificam como "tendeiros do pinhão", suas relações com a dinâmica da rodovia, dentre outros aspectos.

Em termos de literatura que aborda o tema, encontramos obras que revelam questões como, por exemplo, a economia da tradição (PECQUEUR; ZIMMERMAN, 2004), o valor da tradição no horizonte mercantil (CERDAN; VITROLLES, 2008), os saberes tradicionais e sua sociabilidade técnica (SABOURIN, 2001), a territorialidade étnica (PECQUEUR, 1996) e gastronômica. Esses elementos nos auxiliam para a compreensão de alguns dos processos presentes no cenário empírico que analisamos.

Partimos do princípio de que os elementos culturais que produzem certa identidade étnica de grupos passam a ser lançados como estratégias adotadas pelos indivíduos em suas interações no âmbito mercantil, em suas vendas nas tendas, e nas casas, pois fazem com que eles não só vejam o seu pertencimento 
étnico, como também, ao mesmo tempo, produzam as suas distinções e idealizações. O patrimônio cultural é uma dimensão de tempo, uma herança de geração a geração que expressa bens e valores materiais e imateriais. Isso é capaz de constituir um horizonte contínuo de transmissão de princípios e crenças, de saberes e modos de fazer e de viver que caracterizam um grupo social em um determinado lugar e tempo (SANT'ANNA, 2003). Tradições locais passam a ser reconstituídas pelo canal mercantil das unidades familiares, as quais reforçam correlações identitárias do produto e acabam por produzir e otimizar redes mercantis tradicionais (CERDAN; VITROLLES, 2008, p. 191), por meio de vendas diretas entre produtor e consumidor. Desse modo, há recursos e fatores locais que se territorializam (FERRARI, 2011) a partir da percepção e das estratégias dos grupos sociais envolvidos. Nesse sentido, reforçamos a ideia de que há, no grupo em questão, um éthos cultural (SABOURIN, 2009) que é identificado historicamente pelo território do vivido e pelas relações sociais de produção, principalmente na organização da vida no tempo da economia pastoril na região. Algo que se expressa em novos formatos e situações do cotidiano econômico e relacional das pequenas unidades de produção no meio rural em questão.

A partir de tais considerações, entendemos que as práticas econômicas desenvolvidas por meio das tendas e/ou diretamente nas unidades familiares são simbolizadas por sentidos sociais e culturais (LERICHE, 2008), que identificam sujeitos e espaços sociais. ${ }^{5}$ Os sentidos e os conteúdos culturais (CERDAN; VITROLLES, 2008) passam a ser importantes na definição da

\footnotetext{
${ }^{5}$ Esses "sentidos sociais e culturais" estão em correlação com o que definimos, anteriormente, como "potencialidades territoriais", porém agregamos as trocas mercantis aos vínculos entre produtores e sua identidade social, isto é, a identidade étnica e alguns produtos de sua pauta gastronômica. São valores e recursos que são otimizados mercantilmente, vínculos societais de longa data e que identificam sujeitos sociais em suas capacidades de produzir mercados a partir de relações e identidades de grupos. Ao se falar de pinhão na região não há dúvida que logo é identificado aos tendeiros, assim como o feijão e a erva-mate.
}

identidade de grupos, na tipicidade e autenticidade de produtos, porque identificam sujeitos sociais e coletivos. Tais processos, geralmente, materializam-se nas expressões artesanais dos agricultores-comerciantes.

A nossa análise tem como problema de fundo os fatores, as estratégias e as racionalidades mercantis e de organização produtiva que são reproduzidas e redefinidas de forma a constituir, historicamente, um éthos caboclo ${ }^{6}$ relacionado à terra, às lides pastoris e familiares enquanto unidade produtiva e, também, à transmissão de saberes. Desse modo, queremos demonstrar esses processos e entender como eles ganham otimização na esfera mercantil dos tendeiros. Ou seja, em termos de questionamento: é possível indagar de que modo os saberes "antigos", os produtos denominados "crioulos" e características tradicionais da vida desse grupo são valorizados e referenciados nos processos de troca? De que forma elementos da tradição ganham visibilidade nos processos de desenvolvimento regional (Festa do Pinhão, artesanatos em couro, agricultura dos produtos "crioulos" etc.)? Quais são os elementos que dão dinamismo e continuidade histórica aos saberes e que se tornam fundamentais para a sobrevivência das unidades familiares de produção em sua lógica territorial e mercantil?

A estrutura deste texto inicia com a análise de alguns elementos que configuram um éthos, um modo de ser do caboclo, pequeno agricultor da região, que possui uma longa história de trabalhador da estância pastoril "dos campos de Soledade" e como, aos poucos, com a crise de tal setor, o caboclo foi inse-

\footnotetext{
6 A referência à noção de éthos busca enfatizar um modo de ser, uma característica que identifica, historicamente, determinados grupos sociais. É um conceito que auxilia na delimitação de uma identidade social de grupos, que configura uma história incorporada e que se relaciona no tempo com os referenciais que os produziram. No caso em questão, o termo caboclo deve ser entendido neste texto como um horizonte étnico, mas também a partir de relações com processos culturais mais amplos. Processos que se relacionam com o trabalho ligado à terra, com a relac̃o com a nutera (plentágua, otas, tera), com a noc̃o de propriedade

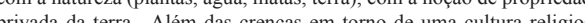
considerada "popular", dos saberes que vão se reproduzindo com forte dimensão de uma economia de subsistência e em correspondência com os limites que o processo histórico de subalternização, que lhe foi imposto por vários sujeitos, produziu. Uma discussão sobre éthos camponês pode ser encontrada em Bourdieu (1998).
} 
rindo-se na pequena produção agrícola e na venda direta na beira de rodovia. Posteriormente, iremos demonstrar a correlação existente entre os elementos étnicos do grupo em questão com a dinâmica da produção mercantil direta, buscando perceber como fatores da tradição vividos e dos saberes da unidade familiar no meio rural, redimensionados pela lógica mercantil atual, são otimizados, redefinidos e redimensionados em termos de sentidos e de intenções. Por fim, construiremos uma argumentação que demonstrará como esses processos acabam por identificar territorialidades étnicas, sociabilidades e pertencimentos grupais que se manifestam e se corporificam em produtos frabricados e vendidos no local.

\section{Os sujeitos em seu território}

Os sujeitos sociais que constituem a dinâmica mercantil nas "Tendas do Pinhão" são, em sua grande maioria, caboclos que possuem uma longa história nessa atividade, alguns deles a realizam por mais de 60 anos, porque é um legado de gerações. Esses caboclos formam, assim, um grupo social que, geralmente, tem a sua origem vinculada às fazendas pastoris da região da Serra do Botucaraí, mais precisamente dos "campos de Soledade", como entrevistados costumam fazer referência. Com a crise da economia pastoril no estado do Rio Grande do Sul, entre as décadas de 1950 e 1970, grande parte desses "trabalhadores das fazendas de gado" (em geral, peões) conseguiu adquirir uma pequena fração de terra na região que, na época, pertencia à Soledade (hoje, municípios de Fontoura Xavier e São José do Erval). Para sobreviver, eles passam a exercer pequenas relações de comércio na beira da rodovia, BR 386, na região de serra, em uma extensão de aproximadamente $10 \mathrm{~km}$, em que o epicentro é vila rural, denominada de Vila Assis.

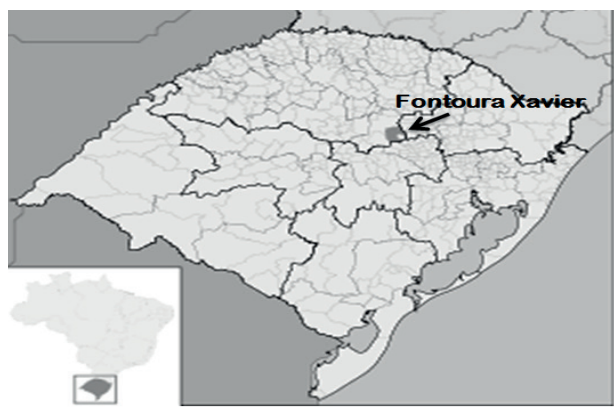

Figura 1. Município de Fontoura Xavier, espaço central de nossa análise empírica. Fonte: elaboração de Cleber Pagliochi.

Esses "Tendeiros do Pinhão", como também são atualmente conhecidos e auto denominados, desenvolvem uma pequena agricultura de base familiar, pois comercializam os seus produtos e os adquiridos de outros pequenos agricultores, inclusive, de outras regiões do estado. Somam-se em torno de 70 tendas nos dois municípios elencados, com funcionamento normal e seqüencial, porém, algumas outras funcionam em apenas alguns períodos do ano, em particular no inverno, quando da cultura do pinhão e/ou "no forte da safra do feijão". Observemos, nesse sentido, a narrativa de uma das entrevistadas:

"A gente se criou no campo, lidando com as criações, depois isso tudo virou roça, o gado se foi, os granjeiros vieram e tomaram conta disso aqui, daí, meu pai comprou um pedaço de roça nessas tigüera [terras dobradas e com matas] e estamos até hoje. [...], a tendinha começou pequena, depois daí com o asfalto e com as melhoras recentes ficou bonita" (Joselma, tendeira entrevistada; há mais de 40 anos na atividade, reside na Vila Assis).

O município de Fontoura Xavier possuía, em 2010 (Censo Demográfico de 2010), uma população de aproximadamente 12 mil habitantes, com mais de $60 \%$ residindo no meio rural e sua topografia é montanhosa. Essa cidade está inserida numa região de serra, com muitos campos nativos e matas, e 
ainda com grande presença do pinheiro (araucária). O pinheiro é o que identifica os tendeiros: há, nesse sentido, uma grande vinculação cultural e territorial dos caboclos com o mato e, em particular, com o pinheiro. Veremos isso mais adiante.

Como já mencionamos, os pequenos agricultores-comerciantes ("tendeiros") formam unidades familiares com grande trajetória familiar de trabalho na cultura pastoril e no extrativismo da erva-mate e da madeira (araucária e cedro) e do pinhão. Esses agricultores produzem assim uma gama de produtos variados, em grande parte, na forma artesanal, conservam saberes e os expressam em produtos, mas que têm na cultura do pinhão, do feijão e do couro as suas referências principais.

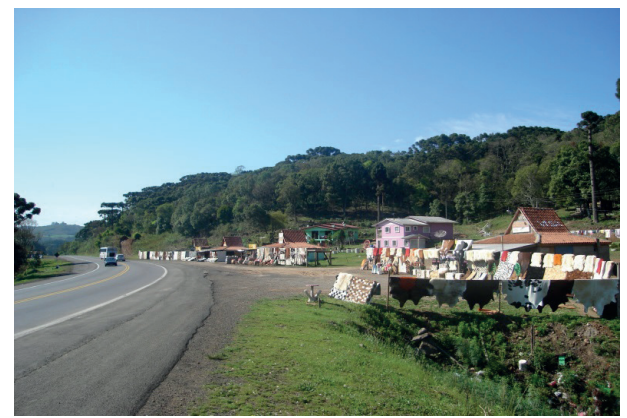

Figura 2 - As tendas de "beira de estrada" em Fontoura Xavier. Nessa região montanhosa, muitas matas são preservadas e, em seu interior, o pinheiro passa a ser o produto por excelência. Fonte: dados da pesquisa

A cultura camponesa de identidade cabocla já foi muito analisada no Rio Grande do Sul, mas sua ênfase é dada na particularidade de seu contato, acesso e cultivo na terra, bem como em sua concepção em torno da propriedade privada da terra. Isso, sobretudo, em sua diferenciação em vários aspectos das concepções de grupos europeus que colonizaram boa parte do estado do Rio Grande do Sul e, em particular, o centronorte (ZARTH, 2002). Os processos de colonização no estado incluíram, quando o fizeram, marginalmente o caboclo, em razão de sua relação com a terra não se adequar à filosofia do progresso idealizada por agentes públicos no período (principalmente nas primeiras décadas do século XX). Essa realidade, somada a já existente de subalternização em inúmeras situações e relações de trabalho nas estâncias pastoris, junto aos grandes produtores e proprietários rurais na indústria extrativista (madeira e erva-mate), fizeram do caboclo, de uma forma geral, um excluído das dinâmicas promotoras do desenvolvimento na região centro-norte do Rio Grande do Sul. Isso revela-se nas inúmeras estratégias produtivas e mercantis que o caboclo lançou mão para fazer frente aos limites impostos e desenvolvidos para sua sobrevivência. A venda na beira de estrada de produtos por ele fabricado é expressiva dessa realidade.

\section{O comércio de beira de estrada: si- nergias e logística}

O comércio "de beira de estrada", segundo os entrevistados, começou em tornode 1935. Nesse período, houve a colocação de pequenas tendas de madeira e lona; porém, era um processo que obedecia a outra lógica, ou seja, buscava atender a carreteiros que levavam produtos da região para o pé da Serra do Botucaraí, principalmente para a região de Santa Maria e Vale do Taquari. Em geral, eram produtos confeccionados em couro devido à intensa economia pastoril que se desenvolvia na região do topo de tal serra, bem como produtos confeccionados em madeira (gamelas, cabos, artesanatos em geral). As tendas eram sazonais ou "quando tinha produtos, principalmente o feijão e o pinhão, esses eram produtos nossos daqui, né" (Entrevista direta com uma ex-tendeira, de 83 anos, na cidade de Soledade). De acordo com esta interlocutora, havia sintonia com os saberes adquiridos e os produtos desenvolvidos: "era uma forma da gente sobreviver, porque saímos da fazenda [pastoril] sem nada [...]; a estrada ajudou a gente, porque aqui 
passava gente, daí resolvemos botar um comerciozinho, da gente mesmo, só de produto que saía da rocinha”.

Porém, é, a partir dos anos de 1970, que esse processo mercantil dos tendeiros na rodovia ganha corpo. Nesse sentido, há o depoimento de Juraci da Silva, tendeira há mais de três décadas: "Vínhamos de carroça para vender, pois necessitávamos daquela venda para sustentar nossa família. Com o tempo, montamos nossa tenda e estamos até hoje; isso faz, eu acho, uns 40 anos".No início dos anos de 1970, grande parte da pequena agricultura na região da serra tentava readequar-se ao novo formato mercantil das unidades que foram vítimas da crise da pecuária no estado e da redefinição produtiva tendo a cultura da soja como o seu carro-chefe.

Os produtos como o milho, o feijão, o fumo, a mandioca, o extrativismo da erva-mate, da madeira e do pinhão tornaram-se intensos. A pecuária era desenvolvida para consumo interno e para possíveis vendas diretas de produtos não consumidos nas unidades. Algumas unidades, como nos disse um feirante, produziram animais (suínos e vacas leiteiras para a venda direta e in natura do leite), além de salames, torresmos e outros subprodutos. Muitos dos atuais tendeiros buscaram adaptar saberes incorporados em produtos na dinâmica mercantil das vendas diretas na rodovia. Um tendeiro entrevistado disse-nos que "com a grande circulação de carros na BR-386, fizemos tenda de madeira para vender produtos que plantávamos na roça, vimos aí uma forma de ganhar alguma coisa, já que a roça era pequena [...], isso já faz mais de 50 anos" (Juraci da Silva, entrevista direta no local da tenda; o mesmo reside no meio rural próximo da sua tenda).

Com a abertura e concretização da referida $\mathrm{BR}$, entre as décadas de 1960 e 1970, os caboclos ampliaram os negócios e a produção agrícola. Por isso, passou a haver maior possibilidade de venda sem necessitar ir a Soledade e, aos poucos, foram acontecendo melhorias e ampliações da infra-estrutura e dos produtos ofertados. No depoimento do Sr. Gilmar (tendeiro considerado "maior e mais modernizado hoje"), "com a abertura da estrada, os caboclos podiam ganhar dinheiro com o trabalho na roça vendendo os produtos agrícolas, mas isso é de tempo atrás; tem gente aqui que vem desde lá pelos anos 40 com isso, sempre vendendo algum pouquinho". 7

Verificou-se, por meio das narrativas, que muitas mulheres começaram a vender produtos artesanais que elas mesmas faziam. Esses produtos eram de trança de palha para montarias de cavalo e para os carroceiros. Segundo Terezinha da Silva, tendeira de 65 anos, "sempre fizemos muito produto de couro, é do feitio antigo nosso aqui né; [...]; resolvemos vender produtos que a gente aqui plantava, da rocinha, e deu certo".

O relato de Marlene da Silva evidencia que existe, entre os tendeiros, uma "convivência em grupo, a gente é um grupo parelho, têm os mais fortes e têm os mais fracos, mas somos iguais, a gente trabalha no conjunto". De acordo com a tendeira, "às vezes um precisa sair, outro fica e toma conta da tenda do outro, né; deu pra diversificar a produção para nossa família e para a venda; aqui é tudo agricultor pequeno, pobre né; então as tendas vieram pra ajudar, né".

Percebe-se que a agricultura de pequena escala é diversificada, em correspondência com a topografia e a reduzida estrutura fundiária (dos entrevistados, o que mais possuía terra, totalizava 12 hectares). Esse tipo de agricultura encontrou nas possibilidades de comércio "de beira de estrada" um processo sinérgico, ampliado de referenciais, indutor de novas alternativas (artesanato em couro, argila, madeira etc.), de divisão de trabalho e

\footnotetext{
${ }^{7}$ Não conseguimos ilustrações (fotografias) e nem documentos sobre o início desse processo de venda na rodovia, principalmente em termos de autorização do DAER e de outros órgãos municipais. Acreditamos que tenha sido um processo informal e sequente, como também sazonal, de ofertas e vendas de produtos, sem um planejamento e autorização pública. Esse processo só vai acontecer no final do século XX e nos primeiros anos do século XXI, com a modernização arquitetônica, logística e a organização em associação.
} 
de saberes no interior das unidades. Ao mesmo tempo, todos os entrevistados enfatizaram a importância "da roça", de ter um espaço para plantar:

“Sem plantar a renda é mínima; aqui a gente usa mais o braço, pouca técnica, pouco ou até nada de veneno, então dá um lucrinho, né; a gente tira muito do mato, o pinhão, o nó [de pinho], a lenha, a erva, agora estamos também fazendo ervas pra chá, tudo aqui é coisa que a gente já se envolvia, né. [...]. Fizemos muitos artesanatos com couro e argila, na madeira também; o problema é que não tem gente pra tanto e os novos vão prá cidade ou não querem aprender, não é". (Entrevista direta com Rosane; tendeira há mais de 20 anos; reside no meio rural de Fontoura Xavier).

A interlocutora revela a aplicação de conhecimentos adquiridos pela história de vida de seu grupo familiar, o que demonstra também a preocupação com os jovens que, por estudarem na cidade e serem atraídos pela vida urbana, reduzem a possibilidade de transmissão de conhecimentos e de envolvimento nas atividades das tendas. Isso, por consequência, resulta em uma produção agrícola que, segundo a entrevistada, "exige muito serviço, não se pára, é todo o dia na lida; sem produto não adianta abrir a tenda e, comprar só dos outros, daí não rende nada".

$\mathrm{Na}$ entrevista com Gilmar, ele diz que "a ideia de meu pai é que a gente nunca saísse da agricultura, mas é difícil segurar os filhos hoje em dia; enquanto der para ir tocando, vamos indo, mas os filhos se envolvem pouco aqui". Constatamos que muitas mulheres participaram no início do processo de venda na beira da rodovia: "homem e mulher, tudo junto, vendiam; os homens iam mais pra roça, mas gostavam de vir aqui e vender; nós começamos porque não tínhamos dinheiro pra comprar comida pras crianças, né".

Buscamos em nossas entrevistas enfatizar o horizonte dos ganhos financeiros de cada unidade, de quanto as tendas colaboram para a receita das famílias; enfim, dos elementos econômicos que giram em torno das vendas diretas. Porém, foi algo bastante difícil de chegar a uma ideia mais efetiva devido ao conjunto de processos envolvidos, tais como a ausência de custos de produção, de ligação entre a roça e a tenda, além da dificuldade de mensurar o custo da força de trabalho em suas várias diferenciações e faixas etárias presentes na unidade e, também, da mescla entre produtos adquiridos e os produzidos internamente na unidade familiar etc. O que podemos afirmar é que nenhum tendeiro garantiu que recebe menos de um salário mínimo, ou seja, a média estava acima de R $\$$ 700,00 ao mês, sendo que há períodos de pico (safra do pinhão, do feijão, o consumo maior do nó de pinho no inverno, a Festa do Pinhão etc.). São processos que, somados, revelam um conjunto de atividades que são características das pequenas unidades de produção no meio rural. Essa realidade também foi evidenciada em entrevista com o Secretário da $\mathrm{Fa}$ zenda do Município de Fontoura Xavier, que informou que "o importante é que se tenha esse grupo, que possa ser ampliado; nós incentivamos para que reduzam custos, não cobramos taxas de ninguém, só queremos que eles sejam bem organizados".

\section{Família, roça e tenda: sociabilida- des culturais}

A unidade familiar revela ser central nos âmbitos produtivos, mercantis e de reprodução/transmissão de saberes que são incorporados aos produtos. Por ser a família uma unidade de convivência e de produção "é que dá para continuar; ninguém paga gente de fora pra cuidar, alguns só em momentos de maior movimento, mas é a família que lida na terra e nas tendas; muitos produtos são feitos no interior da família" (entrevista com Gilmar, tendeiro, residente no meio 
rural de Fontoura Xavier).

A divisão do trabalho, com alternância entre roça, casa e tenda, faz parte de horizontes das condições de cada família, da organização interna, de saberes desenvolvidos no interior dos grupos sociais. Isso ficou bem visível em nossa pesquisa de campo. Segundo a presidente da Associação dos Tendeiros do Pinhão, em entrevista,

"Isso aqui é coisa bem antiga, os avós aqui falam que tinha já nos anos 40 ou 50. As famílias viam na venda uma forma de ganhar dinheiro, de comercializar o que conseguiam plantar num pequeno pedaço de terra, vendiam bastante feijão, pinhão, erva, madeira, coisas que eles sempre souberam fazer. [...]; hoje não é qualquer um que chega e bota tenda, tem de ser da Associação, tem de ser pequeno agricultor, pra não ser só repassador; o pinhão é o ponto forte, mas tem outras coisas que são típicas também da região, do pequeno produtor aqui, que, como tu vê, é tudo terra muito dobrada, de serra, daí plantam ainda coisas que não têm mais em outros lugares onde é só soja; a erva daqui dizem que é muito boa, as frutas, mas o pinhão é que é muito procurado".

Na narrativa acima, está presente a ligação entre a roça, a tenda e a unidade familiar. Estão presentes, também, alguns requisitos para ser tendeiro, a necessidade de diversificar produtos etc. Nesse sentido, a confecções em cerâmica, os bordados, a tecelagem, os derivados de suínos criados às soltas fazem parte do acervo produzido e ofertado nas tendas, elementos que revelam saberes. Nas entrevistas com Alaídes da Rosa (a mais idosa, com 80 anos), é possível perceber a dimensão das interações entre tendeiros, "ninguém concorre entre nós, os que têm mais dinheiro compram mais, têm mais mercadorias, outros menos, mas isso não faz olho gordo em ninguém". Os entrevistados disseram que há práticas de solidariedade, intercâmbio de informações, participação conjunta para preparar a festa do pinhão; "quando aprendemos a fazer vasos com cerâmica, foi todo mundo que fez os cursos, quem sabia mais ensinou pro outro depois daí". Ainda na mesma narrativa: "quando um tem mercadoria da roça e outro não tem, entre nós mesmos se compramos, alguns trocam ou emprestam, para vender nas tendas, sem lograr o outro".

Porém, evidenciamos algumas críticas entre tendeiros relacionadas ao abuso do preço, à conduta de outros companheiros por venderem produtos que não possuem identidade regional/ local. Além de reclamações sobre a ausência de conservação das tendas, pois "alguns capricham mais, outros esperam pelo poder público" diz, em entrevista, a presidente da Associação dos Tendeiros; um entrevistado nos disse que tem "os que vendem lenha da mata nativa, meio escondido no meio das de eucalipto, essas podem, né". A presidente da Associação dos Tendeiros enfatizou, também, alguns critérios para se inserir no grupo, revelando, com isso, diferenciações, seleções, requisitos, controles e exigências, que, muitas vezes, servem como elementos de proteção aos tendeiros já existentes, dificultando a ampliação da concorrência etc.

Embora ocorram esses processos que revelam certas diferenciações e problemas internos, todos os entrevistados enfatizaram a importância da organização, do fato de que a grande maioria dos agricultores colabora e mantém o grupo unido, com ações participativas e solidárias no âmbito familiar e inter-familiar. A tendeira Leonilda, de 70 anos, diz que: "cuidamos [ela e seu filho] das tendas; sobrevivemos do comércio para sustentar nossa família. [...]. Os viajantes passam aqui e querem comprar os produtos caseiros". Maria da Silva diz que o "comércio é de geração para geração da família; todos os comerciantes são filhos de comerciantes; tem um passado que continua aqui, viu". Nesse sentido, ela dá ênfase à solidariedade ao 
dizer que "a gente se troca informação de uma coisa ou outra, tem aqui vez que um cuida da tenda do outro, quando não tem mercadoria aqui, eu informo onde tem [...], porque sabe que todos precisam disso". Nadir da Silva diz que "eu e meus irmãos somos comerciantes tendeiros. Sempre ensinei meus filhos para a profissão de vendedor. [...]. Aqui pelo menos temos produtos caseiros para dar sustento à família". Na narrativa de Sueli, "a terra é o nosso sustento maior, porque é dela que vem o produto aqui. [...]. A tenda sem a terra rende pouco, só que tu tem de plantar, não dá pra pagar prá outros fazerem; a gente aqui por isso se ajuda muito, trocando serviço".

\section{Modernização, conservação e novos produtos}

No final do século XX, com a modernização da rodovia e as melhorias nas condições de vida dos pequenos agricultores-comerciantes, os processos de comercialização foram ampliados. Principalmente, nesse contexto, o artesanato em couro, que é expressivo não só de uma vida na fazenda pastoril regional, mas também importante para a vida de muitos dos atuais tendeiros. Muitos vasos são fabricados no local, que também expressam um saber adquirido e otimizado no processo de troca. Artesanatos confeccionados em madeira, produtos da "comida cabocla", como nos disse uma tendeira, a erva-mate, dentre outros, representam horizontes da tradição do "crioulo". Isso porque obedecem a processos sócio-técnicos de saberes e conhecimentos elaborados que são transmitidos, dinamizados, adaptados e intercambiados através de canais informais, além de cursos que são feitos por tendeiros/as (viabilizados pela Emater, Prefeitura e outros).

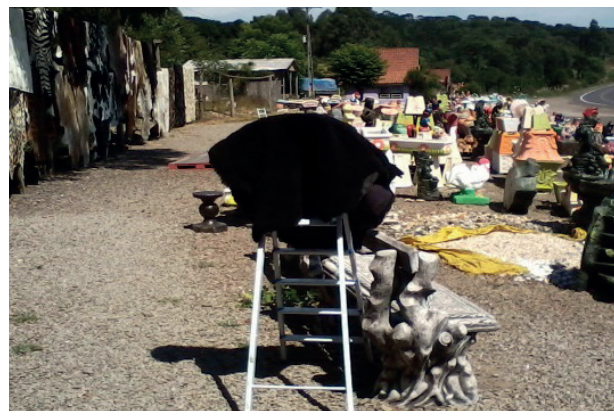

Figura 3 - Nas tendas, percebe-se a existência de tapetes em couro, fruto de saberes nas lidas nas fazendas de gado, características da região até há algumas décadas atrás.

Fonte: dados da pesquisa

A importância da Emater (assistência e aprendizagem rural) é enfatizada pelo fato de que tal entidade contribui para dinamizar saberes aprendidos e/ou readaptados e incorporados em produtos, em técnicas de conservação, em estilos de embalagem, em layout do produto nas tendas, na esfera da produção e/ou da confecção. A Emater está muito presente em meio aos tendeiros, pois com auxílio prestado através de políticas públicas do governo estadual, no início do século XXI, as tendas também foram modernizadas. O que oportunizou a incorporação de novos estilos arquitetônicos, novos formatos para demonstração de produtos, readequação da malha asfáltica em razão da necessidade de estacionamento para carros de clientes e consumidores, dentre uma série de outros elementos.

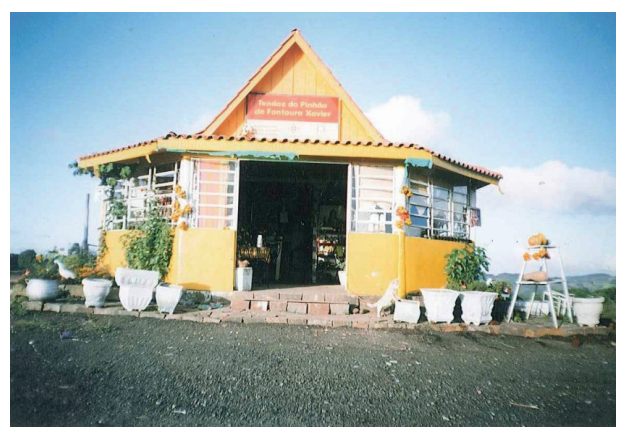

Figura 4 - Formas padronizadas atuais das tendas de "beira da estrada". Fonte: dados da pesquisa 
O pinhão sempre foi o produto central, porém, com a ampliação e melhoramento na rodovia, ele também ganhou maior visibilidade, diversificação de formas de seu consumo e conservação, também passou a fazer parte de receitas de bolos, pães, bolachas e doces em geral. A abundância da araucária (o "pinheiro") é ainda visível na região, em terras "dobradas" sua presença se faz sentir; "o pessoal não pode mais derrubar agora, né", então, tornase uma fonte de renda para os tendeiros.

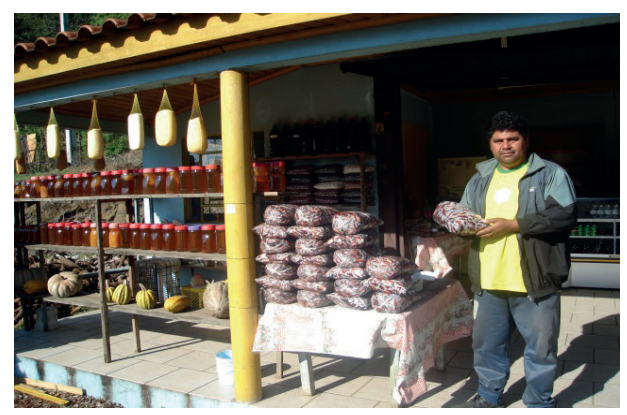

Figura 5 - O pinhão é vendido "na maior parte do ano; já é marca nossa; fizemos muita coisa com ele".

Fonte: dados da pesquisa

Os camponeses diversificam muito a produção, "quanto mais produto variado melhor é; o pessoal quer bastante produto aqui nosso, da terra, coisas que nós sempre soubemos fazer". A valorização econômica dos produtos que os caboclos "tiram da terra" e são vendidos carregam consigo essa dimensão do rústico, do equilíbrio entre homem e natureza. "Ninguém aqui derruba um pinheiro, em vez, planta; eu incentivo meu filho pra plantar; faz mais de 30 anos que sobrevivemos aqui mais com o pinhão", comenta uma tendeira idosa entrevistada.

Outra senhora, que há mais de 50 anos integra a vida na roça e nas tendas, devota do Monge João Maria (figura da cultura popular religiosa do caboclo, muito presente na região em estudo), afirma que procura fazer como ele [Monge João Maria] sempre dizia e fazia: "preservar a natureza para poder criar os bichos nela, é a natureza que cuida e cria deles, nós só damos uma mãozinha, um milhozinho que a gente mesmo colhe" (referindo-se às galinhas, coelhos e porcos criados sem amarras). A reinvenção mercantil desses processos é absorvida por culturas alimentares "de uma época" e que "quase ninguém tem mais", o que acaba identificando sujeitos em seus territórios específicos.

\section{Identidades e produtos: otimização mercantil e reprodução cultural}

A promoção de identificação de grupos (no caso aqui, os caboclos que são camponeses e tendeiros) auxilia na dinâmica mercantil das atividades desenvolvidas e/ou extraídas do local $\mathrm{e}$, nessa territorialidade com identificação grupal (SABOURIN, 2009; PLOEG, 2006), elementos materiais e imateriais estão incluídos. Há o destaque dos produtos e dos agentes locais, ambos correlacionam-se (CERDAN; VITROLES, 2008), valores da tradição que ganham otimização mercantil, que estão em adequação com a denominada economia da qualidade. Esta noção revela tendências de consumidores em adquirir produtos com identificação de "natural", "crioulo", "sem agrotóxico", "feito a mão", com identidade regional em relação a determinados grupos, bem como com identificação de tempos vividos em outras épocas pelos próprios consumidores. Um dos tendeiros nos disse que o consumidor "pede isso", e que, devido a tal solicitação, o próprio tendeiro faz questão de identificar o produto com o local, de modo a informar o consumidor sobre a forma, a procedência e os ingredientes do produto.

“A galinha caipira é criada solta, é das raças crioulas nossas; tem gente que vem aqui buscar ovo pra chocar, pras crias deles. Caminhoneiros de longe compram ovos aqui pra chocar lá. [...]; o salame o pessoal sabe de que porco que vem; é uns bichos criado solto, sem químico, né; eu vendo 
muito torresmo, tem um comprador lá de Chapecó que diz não aguentar comer os torresmos dos frigoríficos de lá; ele, quando passa, pega sempre aqui. A gente explica, conversa com eles, né, uns dizem, 'há isso eu comia quando morava pra fora"'. (Paulo. Tendeiro, entrevistado, residente na Vila Assis).

O interlocutor acima revela signos de qualidade territorial e cultural que são impressos aos produtos; na verdade, são potencialidades territoriais $^{8}$ que as próprias condições dos pequenos agricultores produziram no decorrer de sua história no local. Isto é, formas de reinventar patrimônios culturais locais, reforçando o sentimento de pertencimento dos atores (caboclos) ao seu território, ao seu modus vivendi, a sua trajetória de vida, de identidade e de pertencimento territorial e social. O pequeno agricultor vende os produtos de sua roça, do seu jeito de plantar, "as sementes ainda crioulas". Segundo depoimento de um tendeiro, "vem gente aqui pra pegar do nosso feijão, das ramas de aipim aqui, porque são ainda as nativas, as crioulas, coisa que não tem mais por aí, nós ainda conservamos". Do pinhão, o pequeno agricultor-tendeiro aprendeu a fazer paçoca, pães, cucas, bolos; "a festa do pinhão faz a gente mostrar muito produto novo, formas novas de aproveitar o produto, as coisas novas que aprendemos, com a madeira, a cerâmica, o couro, o pinhão e com as carnes". Sobre os suínos e a quantidade imensa de salames que são vendidos, um entrevistado disse que

"agora nem tanto, por causa do asfalto, mas mesmo assim, fizemos cercados fora do chiqueiro, para o sustento da família e vendemos também nas tendas algum salame, morcilha,

${ }^{8}$ Entendemos por "potencialidades territoriais" capitais culturais, identidades de grupos, que se correlacionam com produtos, com a vida e o trabalho na terra; sujeitos sociais que, pela experiência e identidade como peões de estâncias pastoris na região e, posteriormente, como pequenos agricultores, adquiriram saberes em intercâmbio constante com outras esferas e grupos sociais. Essas "potencialidades territoriais" fazem identificar sujeitos e produtos, saberes e trocas mercantis, as quais são otimizadas nas tendas em questão. banha, torresmo bastante; aqui se tu produzir, tu vende; a natureza deu muito pra nós, mas nós também tiramos dela; trabalhamos na roça, compramos de outros pequenos aqui que nem nós, mas que não tem tenda ou tiveram e desistiram" (Luis, tendeiro há 26 anos, reside no meio rural de Fontoura Xavier).

O caboclo-tendeiro também manifesta seu éthos cultural ligado à vida do campo em seus produtos de montarias (pelego, selas, tapetes, chiripás, palas etc.). A vida do campo, da fazenda, presente nas lembranças dos tendeiros, é otimizada na esfera mercantil: "ainda que muito produto não venha daqui, mas é aqui que é vendido, porque tem muita gente aqui ligada a essa vida da fazenda, né, que mora ou que passa por aqui; vendemos muito disso aqui, é o nosso forte".

Percebemos que, a partir de tradições locais, ou seja, dos elementos que os caboclos identificam como "de uma vez", existe uma forma de contribuição na economia doméstica, pois os tendeiros constroem identificações geográficas pela promoção de produtos típicos, reforçando a dimensão identitária do produto, como forma de otimizá-lo nas redes mercantis tradicionais (CERDAN; VITROLLES, 2008). Ou seja, nas vendas diretas em casa ou nas tendas para pessoas "que se identificam e gostam desses nossos produtos; na festa do pinhão o pessoal diz que vem pra cá porque o pinhão daqui é melhor, tem um gosto melhor". Por isso, os espaços se localizam; há fatores locacionais que se territorializam (FERRARI, 2011) como resultado de estratégias de grupos e sujeitos que se definem na produção de coletividades, organizando, distribuindo e coordenando recursos, comportamentos e ações. Há uma vinculação entre o que eles consideram como tradição ("costumes nossos") e as dinâmicas para maximizá-la na esfera mercantil. Desse modo, entendemos que em meio aos tendeiros, em suas práticas cotidianas de trabalho e de vida social, 
reproduz-se e redefine-se um mercado dos bens simbólicos, principalmente da vida na cultura pastoril e na terra/roça, o que possibilita transmitir ideais e valores de pertencimento, que, sem dúvida, colaboram para a reconstrução e definição seletiva da identidade dos sujeitos sociais em questão.

Os camponeses diversificam muito a produção, "quanto mais produto variado melhor é, o pessoal quer bastante produto aqui nosso, da terra, coisas que nós sempre soubemos fazer", diz Gilmar Batisti em entrevista em seu local de venda. Já mencionamos que há uma grande identificação do caboclo da região com a cultura da erva, da madeira e do pinhão. No entanto, há também com a diversificação das culturas da roça, pois existe uma intensa ligação com a terra, já que esta transmite a identidade do caboclo, o seu pertencimento produz uma simbiose histórica, de gerações, de obrigações e de possibilidades de sobrevivência. Um dos tendeiros assim revela:

\begin{abstract}
"A gente é filho de pequeno agricultor [...]; se dependesse de mim, eu nunca vou sair do interior. A gente se criou no interior, sabe o quanto que é bom. Tá louco! Não tem coisa melhor! [...]; a ideia do meu pai é que nunca nós saíssemos de lá, né. Ele conseguiu comprar um pedacinho de terra, mas daí com um monte de filho, não dava mais pra continuar comprando terra. Pra gente que sente [...] a gente se criou na roça $[. .$.$] . Quando a gente vê$ criança que se criou e mora na cidade e vem pro interior, né, aí a gente começa a ver que maravilha que é ta na terra". (Entrevista direta com Gilmar Batisti, tendeiro que "vem de avô, meu pai e quero ver se passo para o filho").
\end{abstract}

O entrevistado diz que busca sempre "informar o consumidor sobre a forma, a procedência e os ingredientes do produto, só não digo como consigo conservar o pinhão por mais de seis meses, isso não!". Percebemos, então, que o caboclo manifesta a sua cultura por meio do ramo comercial, pois vende os produtos de sua roça, do seu jeito de plantar, "as sementes ainda crioulas".

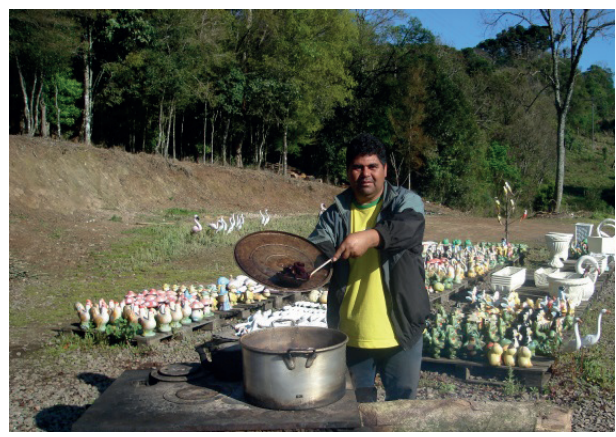

Figura 6 - Sementes "crioulas dos caboclos" são procuradas para "fortalecer aquelas que a técnica enfraqueceu", diz um dos tendeiros. Fonte: dados da pesquisa

Um dos entrevistados disse-nos que "vem gente aqui pra pegar do nosso feijão, das ramas de aipim aqui porque são ainda as nativas, as crioulas, coisa que não tem mais por aí, nós ainda conservamos". Do pinhão, o pequeno agricultor-tendeiro aprendeu a fazer paçoca, pães, cucas, bolos; "'a festa do pinhão faz a gente mostrar muito produto novo, formas novas de aproveitar o produto, os coisas novas que aprendemos".

Em quase todas as tendas, o pinhão é cozido na água ou assado na brasa ou na chapa de fogões ao ar livre, em frente às tendas.

"Isso é a nossa marca; aqui tu chega, tá o pinhão pronto, tu podes levar e comer aqui, em geral, o pessoal enche a barriga aqui e depois leva; o que leva paga, o que come aqui só se alguém quer dar alguma coisa. [...]; meu irmão trepa nos pinheiros, eu já não consigo mais, mas ele é treinado pra isso. [...]. Quem não tem muito mato na terra, aluga um mato e tira os pinhão, outros arrumam com a turma mesmo. O pinhão é o nosso forte, ele chega de durar até sete mês, é de março até setembro. [...]; nos conhecem aqui pelo pinhão" (Leonir. Tendeiro, entrevistado, que diz ter nascido "dentro da tenda"; reside no meio rural de Fontoura Xavier). 


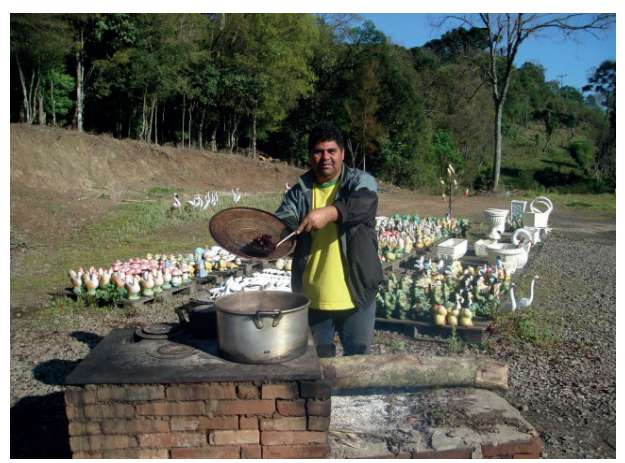

Figura 7 - Pinhão cozido para ser vendido e/ou consumido junto à tenda na rodovia. Fonte: dados da pesquisa

\section{Saberes, festejos e sua dimensão mercantil}

As lógicas econômicas necessitam dos sentidos sociais e culturais localizados e identificados como marcas de sujeitos sociais (LERICHE, 2008). Tais sentidos são construídos por grupos sociais ao longo de sua história. Porém, não há dúvida de que a lógica da racionalidade das trocas capitalistas não se baseia e, tampouco, desenvolve esses valores humanos e sociais (SABOURIN, 2009), mas, ao mesmo tempo, não os ignora. São processos relacionais, que implicam negociações, antagonismos que se confrontam, princípios que são lançados e que podem se excluir, como também complementamse. Os conteúdos culturais (CERDAN; VITROLLES, 2008) que dão notoriedade a um produto são explorados em sua natureza imaterial (saberes, formatos, sentidos, identificação etc.), ganhando atribuição de autenticidade e tipicidade, o que engloba fatores naturais e humano-sociais (LERICHE, 2008).

As condições e as formas de produzir também resultam de culturas e de histórias, assim como servem de atrações no processo mercantil e de troca em espaços definidos e específicos, que carregam noções de pertencimento territorial e cultural.
"Eu fui um dos primeiros que tive a ideia, depois todo mundo me imitou; o couro, as montarias, era coisa de todo o mundo aqui, só nós não fazíamos; agora todo mundo compra, alguns até são feitos por aqui, mas a grande maioria compra; é bonito ver todos esses tapetes nas tendas; isso identifica muito a gente aqui, o pessoal sabe que tapetes, pelegos, forros, tudo, é encontrado aqui, podem comprar aqui; tem gente de São Paulo, de Santa Catarina tem muito que leva de dúzia, acho que depois eles revendem lá, mas ficam triste quando passam em não encontram" (Tendeiro entrevistado que reside no meio rural de Fontoura Xavier).

Entendemos que essas dinâmicas revelam sujeitos situados que orientam algumas de suas atividades produtivas e comerciais em correlação com sua performance identitária; porém, de acordo com Pecqueur e Zimmermann (2004, p. 17), são também locais que funcionam como "modalidade de financiamento do global", ou seja, que estão em interação com circuitos externos, em inserções múltiplas e sempre captando externalidades (tecnologia, gestão, política, pública, lay-out, conhecimentos, concorrências, pressões de mercado). Entendendo assim, é possível visualizar que os pequenos agricultores constroem e reconstroem passados e presentes em seu cotidiano de trabalho e em suas relações mercantis e de sociabilidades. Eles experimentam ações e redefinem processos em razão de necessidades; (re)elaboram experiências fundadas na cultura e nos processos sócio-históricos de seu meio local e global.

Podemos dizer, ainda, que, em torno de determinados produtos, constituem-se territórios, costumes e valores humanos e simbólicos. Aspectos que não se fundam, unicamente, na dinâmica da intercambialidade mercantil, já que também formam uma ampla e significativa troca de valores ou valores em 
troca. Dimensões materiais e subjetivas, bem como as cunho simbólico-coletivas, podem estar intimamente relacionadas. Isso implica a determinação e conformação daquilo que se considera renda, nos múltiplos e qualificativos espaços em torno do trabalho, nas estratégias e nas racionalidades adaptativas em relação aos ambientes externos e internos das unidades familiares, em seus vínculos ou não a um coletivo de produtores e comerciantes integrados e identificados como "tendeiros do pinhão".

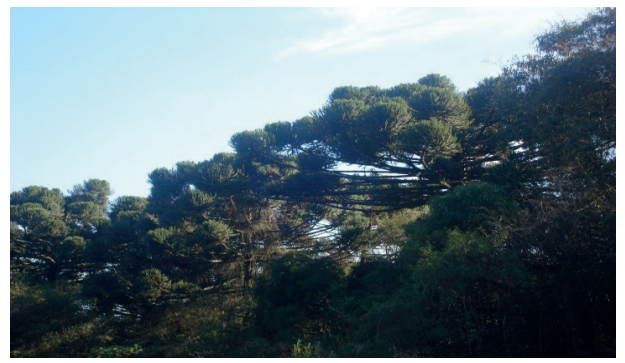

Figura 8 - O pinheiro (araucária) é a árvore que identifica o grupo de caboclos; revela a sua relação com o extrativismo, com a mata e, além do mais, produz o fruto que é o carrochefe da identificação mercantil dos tendeiros. Fonte: dados da pesquisa

$\mathrm{Na}$ perspectiva dos tendeiros entrevistados, o denominado "produto colonial" é revestido de uma simbologia que reproduz tempos, saberes, identidades grupais, nostalgia de consumidores etc., fatores que resultam em visibilidade mercantil. Na narrativa de um tendeiro,

"o produto colonial, esse mais braçal e antigo, as miudezas como a gente diz, vende, dá dinheiro; a gente faz o produto aqui, que nem da cana faz o melado, a rapadura, o pé-de-moleque, do pé de vassoura fizemos a vassoura pronta, de várias frutas sai o suco, do figo a chimia; a gente aprende a valorizar mais o que se tinha e o que se tem, faz o preço, não é. [...], elas fazem curso e aprendem a conservar, a fazer de tudo um pouco; eu vou plantar abóbora no ano que vem pra fazer doces, aqui todos apreciam e ninguém quase planta, antes se dava para as vacas; aqui na beira [do asfalto] quero dessecar tudo e plantar feijão, o pessoal vai ver o feijão plantado, aqui dá feijão por tudo". (Aristides. Tendeiro entrevistado que possui tenda por 17 anos e reside no meio rural de São José do Erval).

Os pequenos agricultores-tendeiros necessitam agregar, de seu horizonte moral e multifuncional, estratégias e ações que se manifestem no coletivo para destacá-lo, principalmente, em festejos e exposições coletivas. As festas são uma das formas de expressão e ritualização da identidade do território. É, também, uma demanda turística e midiática, que não deixa de lado a gastronomia e o envolvimento com o produtor. $\mathrm{O}$ tendeiro se faz presente na festa, auxilia na sua organização, sobretudo, com a extração e a confecção de produtos do pinhão, de modo a encontrar um grande espaço de mercado. Os produtos por excelência dos grupos, no caso, o pinhão, só se evidenciam quando seu valor e utilidade estiverem no interior de um processo produtivo particular e não em outro contexto (PECQUEUR, 1996). Nesses espaços festivos, o pequeno agricultor familiar revela a dimensão da multifuncionalidade, porque aproveita para apresentar, mercantil e simbolicamente, várias ações produtivas, técnicas, culturais, sociais, ambientais, territoriais, morais e comerciais, as quais revelam sua importância enquanto tendeiro, além de estratégias de reprodução e embates sociais e políticos.

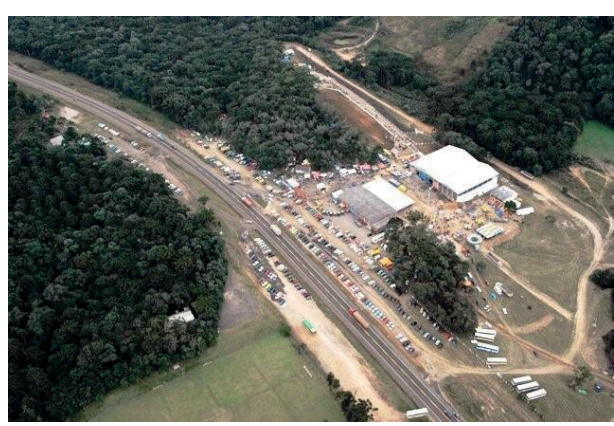

Figura 9 - Vista área do local onde se desenvolve a Festa do Pinhão, em Fontoura Xavier, 
em que os camponeses-tendeiros têm um papel fundamental. Fonte: Assessoria de Comunicação da Prefeitura de Fontoura Xavier.

\begin{abstract}
"Nas festas do pinhão, o pessoal costuma dizer que 'pinhão igual ao nosso não tem'; pinhão para mim é tudo igual, mas é o pessoal que diz; eu acho que porque aqui tem mais e de tanto tempo que fazemos, talvez sabemos melhor o ponto, não é? O pessoal aqui também inventa muito com o pinhão, faz dele muita coisa. [...]. $\mathrm{Na}$ festa, o nosso produto é muito procurado, se vende bastante, não só o pinhão, botamos de tudo pra vender [...]. Na verdade, a gente é tendeiro, mas é da terra, da roça, né". (Valdir. Tendeiro entrevistado, um dos responsáveis pela organização da Festa do Pinhão; possui tenda a mais de 15 anos; reside na Vila Assis).
\end{abstract}

As festas passam a ser momentos importantes de trocas econômicas e de uma economia cultural (CERDAN; FOURNIER, 2007), de dinamismo relacional entre famílias, reafirmações de sociabilidades, em que a cultura popular, através da comilança, das danças e cantorias se ritualiza. As festas, portanto, resultam de iniciativas coletivas e, com isso, dão identidades sociais aos territórios, valorização de mercado "aos nossos produtos" e constituem um sentimento de pertencimento. Isso porque os agentes envolvidos buscam encontrar recursos no território para melhorar a qualidade, a identificação do produto com o local (caboclos, ligados à terra, aos produtos mais naturais da "nossa rocinha"). Tais recursos são, em sua maioria, produzidos e mobilizados por atores em interação com o seu meio; são oportunidades para integrar, renovar, inovar, reconstituir valores e saberes (CERDAN; MARTIN; FLORES, 2008). Esse é um capital social dos grupos (SABOURIN, 2009) e que se fortalece em momentos de ritualidades festivas, permite, com isso, produzir mais sinergias entre atores e territó- rios, formando grupos de pertencimento ("somos das tendas do pinhão"). Ploeg (2006) chama isso de uma "coreografia da recampesinização”, ou seja, estratégias de ação de grupos com forte vinculação e pertencimento cultural e com o território vivido de longa data, que dimensionam a diversificação, o processamento de produtos na unidade, a agricultura de baixo custo, a refundamentação da agricultura na/com a natureza. Nesse sentido, disse-nos um proprietário de uma indústria "caseira" de embutidos (salame e lingüiça), vendidos na sua tenda, que,
"os ricos de agora voltaram a comer o que comiam quando eram pobres; vêm comprá dos pobres o que os ricos não comem mais no dia-a-dia e nós come- mos [...]; eles se identificam com uma vez [tempos atrás da vida na colônia], não é? Sentem saudade disso; nós so- mos os que ainda têm isso, tu não en- contra mais por aí tão facilmente uma carne de galinha caipira pra fazer a sopa de antigamente que todos eles gostam". (Orlando. Tendeiro que possui agroin- dústria artesanal de embutidos e reside no meio rural de Fontoura Xavier).

Esses processos revelam pluriatividades com dimensões agrícolas e não -agrícolas, adentrando por vários canais produtivos com potencialidades mercantis, formas novas de cooperação local, além de melhoramento da eficiência da conversão de insumos em produtos (PECQUEUR, 2008). Muitos tendeiros possuem duas gerações na atividade que correlaciona pequena agricultura e comércio na beira da referida estrada. É o que informa um interlocutor:

"Começamos a vender pinhão e produtos agrícolas que plantávamos e colhíamos de nossas terras. O comércio das tendas passa de geração para geração. Quem assumiu a tenda agora foi meu filho de 27 anos, o qual casou e, para não sair para longe para trabalhar nas firmas, continuou com a profissão de seu pai, o que vinha des- 
de seu tataravô, bisavô, e assim consecutivamente. Todos os meus filhos se criaram comerciando junto com o pai” (Marlene. Tendeira, há mais de 30 anos; reside na Vila Assis).

Outro entrevistado disse-nos que

"Eu queria ter mais mato, capoeira, né; iria plantar muita erva, muito pinhão, criar passarinho; aqui é tudo meio explorado, o pessoal tira muito, mas refaz pouco, poucos plantam o pinhão, tem gente que mete as vaquinhas no mato, elas comem tudo, as árvores novas também e os pinhão que nascem, por mim não deveriam. Gente que comprou mato aqui na beira pra fazer chácara, constroem mansão, mas derrubam tudo, não deixam nós tirar o pinhão, a gente fica até meio constrangido, porque quando tu vê muda muito, né, tu tem um vizinho que tu nem conhece; é gente de Fontoura e de Soledade; aqui é lugar bom de se viver, é serra, topo de serra, então, o ar é bom e tem verde a vontade, né" (Luis. Tendeiro "dos mais antigos"; reside logo atrás de sua tenda em Fontoura Xavier).

A terra para muitos pequenos agricultores continua sendo identificada como patrimônio cultural, lugar da vida, da subsistência da família, espaço da inter-relação com a natureza, dádiva divina e que precisa ser preservada e obedecida em sua lógica produtiva. Desse modo, é possível reconhecer que os territórios possuem riquezas humanas, patrimônios (materiais e imateriais) que, colocados em evidência, interligados aos demais, em âmbito regional, produzem transformações na realidade e passam a ser um grande pressuposto para os processos de desenvolvimento e identidade de grupos. Identidade que não se dá sem uma referência ao passado dos grupos que produziram relações no espaço; por isso, a noção de pertencimento é muito cara para a ideia de território, pois re-aloca o contexto histórico em temporalidades presentes.

\section{Considerações finais}

Ao longo desta pesquisa, percebemos que, junto aos tendeiros, há identificação de uma territorialidade étnica; há uma busca de valorização de patrimônios, saberes incorporados e disseminados no interior dos grupos étnicos, normas coletivas de qualidade, responsabilidades grupais no atendimento e na performance e na qualidade dos produtos, "pra que ninguém estrague o outro". Nesses horizontes relacionais, surgem e se fortalecem as relações de amizade, as alianças, a retribuição, o prestígio, a confiança coletiva, os intercâmbios de saberes e aprendizagens próprios de uma dimensão de intercâmbio sócio-técnico (SABOURIN, 2009). $\mathrm{O}$ que funciona para otimizar os fatores que a dinâmica mercantil atual exige nesse circuitos de trocas diretas entre produtores e consumidores.

Os grupos sociais produzem redes e bases para a convivência, a identificação e o pertencimento social (RAFFESTIN, 1993). Esse pertencimento é que auxilia na produção de um éthos grupal e, junto ao espaço social e mercantil das tendas, vincula, historicamente, produtos e saberes, formatos e relações de longa data com o mesmo grupo. Confiança, interconhecimento, passados comuns, identidades de produtores rurais, obrigações/reciprocidades entre vizinhos, solidariedade, família como unidade de produção, de cultura e de convívio etc., são valores que se imprimem em territórios a partir da identificação de grupos sociais (SABOURIN, 2009).

A partir dessa questão da territorialização de saberes e de sociabilidades identificadas com o grupo (SABOURIN, 2001), torna-se possível considerarmos que há uma re-elaboração dos produtores na sua relação com a natureza, com o que "a natureza tem aqui"; revalorizam-se as matas, as fontes de água, os rios, as árvores nativas (caminha-se por tais locais como espaço de 
lazer e de turismo). Revigoram-se, assim, os potreiros, o adubo orgânico, a criação de "bichinhos", aumentando, com isso, o valor agregado à própria natureza em termos comerciais e simbólicos, "tem gente que vem aqui só pra ver nós tirar os pinhão, é bonito ver trepar e ver as pinhas caírem". Isso tudo tende a reterritorializar identidades de grupos (PECQUEUR, 1996), ou seja, sai de uma esfera do vivido do trabalho (no caso, no espaço do campo, da pecuária e do extrativismo da erva mate, da madeira e do pinhão) para o das relações mercantis nas tendas.

Os valores do patrimônio cultural tendem a estar em consonância com o conjunto das representações que cada grupo social produz, institucionaliza, pratica e transmite por meio de formas variadas de socialização e de interação dos membros e destes com outros de fora do grupo. Desse modo, como vimos, os territórios com identificação de grupos étnicos são constantemente construídos; são processos engendrados por mediadores, legitimados pela história, pela vivência e pela produção territorial. Os grupos sociais ganham contornos e configuração nos produtos, na gastronomia, na origem comum, na vida no meio rural, na roça e na fazenda, porque fazem agregar tradições passadas a determinadas dimensões do presente. Esse é o sentido de herança que a noção de patrimônio imaterial carrega e que os pequenos agricultores-tendeiros buscam reproduzir ao seu modo e com as condições que a dinâmica mercantil atual permite.

Vimos que produtos artesanais, junto aos tendeiros, reconfiguram heranças culturais que grupos sociais apreenderam de diferentes outros grupos de convivência histórica e, também, contemporânea em seus múltiplos tempos e espaços de vida. Portanto, há trocas culturais, étnicas, de saberes adaptados e inventados ao sabor das circunstâncias. Conhecimentos que expressam o que autores denominam de sistemas locais de conhecimento (CERDAN; MARTIN DE SOUZA; FLORES, 2008). O artesanato sempre teve uma relação com o comércio e a agricultura na vida de pequenos agricultores. Essa atividade sempre transmitiu trabalho, valores, técnicas, símbolos, pertencimentos e saberes produzidos e transmitidos no sistema cultural de indivíduos e grupos sociais. A sua transtemporalidade para as décadas mais recentes incorporou uma maior dinâmica mercantil. Os objetos em couro como os laços, as rédeas, o cabresto, as cordas e os instrumentos para montaria e arreiamento em geral, a bainha para facões e facas, o barbicacho, os produtos de lã como uso doméstico de cobertores e colchas, ponchos, blusas, tapetes etc., são expressivos da vida nas estâncias pastoris que as unidades familiares de caboclos produzem e vendem na beira da rodovia (BR 386), na Serra do Botucaraí. Isso faz parte de seu horizonte cultural de longa data, o que é muito valorizado na esfera mercantil; "as tendas sempre estão cheias, o pessoal sabe que é da gente, não é, é de nosso feitio, sempre fizemos isso e, agora, ainda melhorado porque trabalhamos num coletivo, não é", disse-nos uma senhora feirante, confeccionista de artesanato em couro. Por isso, insistimos na ideia de que a dinamicidade mercantil moderna não prescinde, totalmente, dessa tendência de reprodução de saberes da tradição. Aliás, esta última passa a ser maximizada pelos canais mercantis da economia moderna. Os tendeiros são uma expressão disso.

Vimos que os sujeitos sociais estudados são produtores e comerciantes ao mesmo tempo, pois se organizam para efetivar o comércio de seus produtos na beira da rodovia e, também, pressionam o poder público para melhorar a logística e a propaganda das tendas, além de uma efetivação da infraestrutura e da arquitetura desses locais.

Junto com isso, há um amplo processo que os interlocutores informam como sendo expressivo de pon- 
tos de estrangulamentos no interior do grupo, nas mediações, nos processos de troca e na infraestrutura. Interlocutores insistem na presença mais efetiva do poder público municipal em termos de infraestrutura, marketing, participação nas feiras etc. Há o descontentamento de tendeiros em relação à falta de organização política e de representação do grupo junto ao poder público municipal (em particular, de Fontoura Xavier), à padronização de preços, o controle da qualidade de produtos junto aos tendeiros e a falta de participação nas reuniões da Associação. Há, ainda, o temor de que haja duplicação da rodovia na serra e obrigue o remanejamento de tendeiros do local. Além disso, há a ausência de conservação das tendas por parte de muitos tendeiros e o temor deles pela desistência de muitos tendeiros por múltiplas razões etc.

É, portanto, uma realidade dinâmica, expressiva de múltiplos processos econômicos, culturais, históricos, da vida como pequeno agricultor, de um nicho de mercado com características específicas, da multifuncionalidade do pequeno agricultor familiar, de tradições e saberes que se renovam, de limites e enfrentamentos que o cotidiano das relações expressa e produz.

\section{Referências}

1.BOURDIEU, P. La domonation masculine. Paris, Seuil, 1998.

2. CERDAN, C.; FOURNIER, S. Le Système agroalimentaire localisé comme produit de l'activations de resources territoriales. Enjeux et contraintes du développement local des productions agroalimentaires artisanales. PECQUEUR, B.,GUMUCHIAN, H. La resource territorial. Paris, Édition Economica, 2007, cap. 2, p. 103-125.

3. CERDAN, C.; MARTIN de SOUZA; FLORES, M. El patrimônio cultural como um elemento estratégico para el dessarrollo territorial: dos casos de la inmigración italiana en Brasil. RANABALDO, C.; SCHEJTMAN, A. EI valor del patrimônio cultural: territórios rurales, experiências y projecciones latinoamericanas. RIMISP, Lima, 2008, cap. 4, p. 313-332.

4. CERDAN, C.; VITROLLES, D. Valorisations des produits d'origine: contribution pour le développement durable dans la Pampa Gaucha au Brésil. Geocarrefour, n. 83, v.3, p. 191- 202, 2008.

5. FERRARI, D. L. Cadeias agroalimentares curtas: A construção social de mercados de qualidade pelos agricultores familiares em Santa Catarina. Porto Alegre, PGDR, 2011. Tese em Desenvolvimento Rural.

6. LERICHE, F. et al. (Coord.). L'économie culturelle et ses territoires. $\mathrm{Mi}-$ rail, PUM, 2008.

7. PECQUEUR, B. Dynamiques territoriales et mutations économiques. Paris, L'Harmattan, 1996.

8. ris, Syros, 2008.

9. PECQUEUR, B.; ZIMMERMANN, J. B. (Sous la dir.). Économie de proximités. Paris, Lavoisier, 2004

10. PlOEG, J. D. V. der. O modo de produção camponês revisitado. SCHNEIDER, S. (Org.). A diversidade da agricultura familiar. Porto Alegre, Editora da UFRGS, 2006, cap. 1, p. 1356.

11. RAFFESTIN, C. Por uma geografia do poder. São Paulo, Ática, 1993.

12. SABOURIN, E. Aprendizagem coletiva e construção social do saber local: o caso da inovação na agricultura familiar da Paraíba. Estudos Sociedade e Agricultura. Rio de Janeiro, UFRRJ, n. 16, p. 37-61, abril de 2001.

13. SABOURIN, E. Camponeses do Brasil: entre a troca mercantil e a reciprocidade. Rio de Janeiro, Garamond, 2009. 
14. SANT'ANNA, M. A face imaterial do patrimônio cultural: os novos instrumentos de reconhecimento e valorização. ABREU, R.; CHAGAS, M. (Orgs). Memória e patrimônio: ensaios contemporâneos. Rio de Janeiro, DP\&A, 2003, cap. 3, p. 46-55.

15. ZARTH, P. Do Arcaico ao Moderno. O Rio Grande do Sul agrário do século XIX. Ijuí, Editora Unijuí, 2002. 